\title{
Provisional extension to induce complete attachment of an endovascular repair for acute type $A$ aortic dissection with visceral malperfusion
}

Ourania Preventza, MD, ${ }^{\mathrm{a}, \mathrm{b}}$ Oluyinka O. Olutoye II, MD, MPH, ${ }^{\mathrm{c}}$ Subhasis Chatterjee, MD, ${ }^{\mathrm{b}, \mathrm{c}}$

Alice Le Huu, MD, ${ }^{\mathrm{b}}$ and Joseph S. Coselli, MD, ${ }^{\mathrm{a}, \mathrm{b}}$ Houston, Tex

\footnotetext{
From the Divisions of ${ }^{\mathrm{a}}$ Cardiothoracic Surgery and ${ }^{\mathrm{c}}$ General Surgery, Michael E. DeBakey Department of Surgery, Baylor College of Medicine, Houston, Tex; and ${ }^{\mathrm{b}}$ Department of Cardiovascular Surgery, Texas Heart Institute, Houston, Tex.

Disclosures: Dr Coselli participates in clinical trials with GlaxoSmithKline, Edward Lifesciences, CytoSorbents, Bolton Medical, Vascutek Terumo, Medtronic Inc., W. L. Gore \& Associates, and Cook, Inc; Dr LeMaire, with Medtronic, Inc, W. L. Gore \& Associates, Vascutek Terumo, CytoSorbents, and Baxter Healthcare; and Dr Preventza, with Medtronic, Inc, and W. L. Gore \& Associates. All other authors reported no conflicts of interest. The Journal policy requires editors and reviewers to disclose conflicts of interest and to decline handling or reviewing manuscripts for which they may have a conflict of interest. The editors and reviewers of this article have no conflicts of interest.

Received for publication June 29, 2020; revisions received June 29, 2020; accepted for publication June 30, 2020; available ahead of print July 2, 2020

Address for reprints: Ourania Preventza, MD, Baylor College of Medicine, One Baylor Plaza, BCM 390, Houston, TX 77030 (E-mail: preventz@bcm.edu).

JTCVS Techniques 2020;3:61-3

2666-2507

Copyright (c) 2020 The Authors. Published by Elsevier Inc. on behalf of The American Association for Thoracic Surgery. This is an open access article under the CC BY-NC-ND license (http://creativecommons.org/licenses/bync-nd/4.0/)

https://doi.org/10.1016/j.xjtc.2020.06.046
}

Video clip is available online.

Patients with type A aortic dissection (AAD) and mesenteric malperfusion have greater in-hospital mortality risk than patients with AAD without mesenteric malperfusion $(63 \%$ vs $24 \%){ }^{1}$ Using the PETTICOAT (provisional extension to induce complete attachment) technique as a first-line strategy before proximal repair, we resolved our patient's visceral malperfusion.

\section{CASE REPORT}

A 39-year-old man with Marfan syndrome, hypertension, and a history of substance abuse transferred to our facility with rapid-onset, sharp parasternal and abdominal pain, and copious melena. His systolic blood pressure was 170$180 \mathrm{~mm} \mathrm{Hg}$; anti-impulse therapy began. Initial laboratory results included elevated serum lactate $(8.3 \mathrm{mmol} / \mathrm{L})$ and creatinine levels $(1.71 \mathrm{mg} / \mathrm{dL})$. Computed tomography revealed a DeBakey type I aortic dissection extending from the aortic root between the left main and right coronary artery ostia to beyond the common iliac artery bifurcation (Figure 1). Dynamic malperfusion of the celiac, superior mesenteric, and

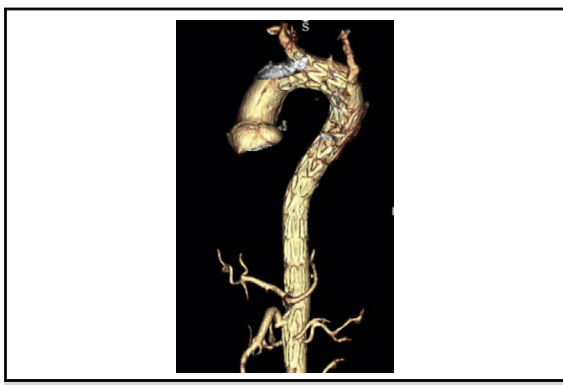

PETTICOAT for visceral malperfusion before proximal repair for type $A$ aortic dissection.

\section{CENTRAL MESSAGE \\ We used the first-line PETTI- COAT strategy with the Zenith Dissection Endovascular System for acute type $A$ aortic dissection and visceral malperfusion, fol- lowed by proximal aortic replacement.}

right renal arteries resulted in occlusion of these vessels. Transthoracic echocardiography confirmed AAD, mild aortic regurgitation, and absence of pericardial effusion.

Because the immediate concern was visceral malperfusion, we used the thoracic endovascular aortic repairPETTICOAT first-line approach. Although we currently prefer to use intraoperative intravascular ultrasonography in endovascular cases, intravascular ultrasonography was not readily available at our institution at that time. In an emergency procedure, 32- $\times 109-\mathrm{mm}$ and $34-\times 161-\mathrm{mm}$ covered Cook Zenith Alpha endografts (Cook Medical, Bloomington, Ind) were placed from the level of the left subclavian artery to just above the celiac artery. Followup angiography showed no flow into the infrarenal or visceral aorta. Therefore, a 36- $\times 180-\mathrm{mm}$ Cook Zenith Dissection Endovascular Stent (Cook) was deployed across the visceral vessels in the true lumen. Angiography showed 


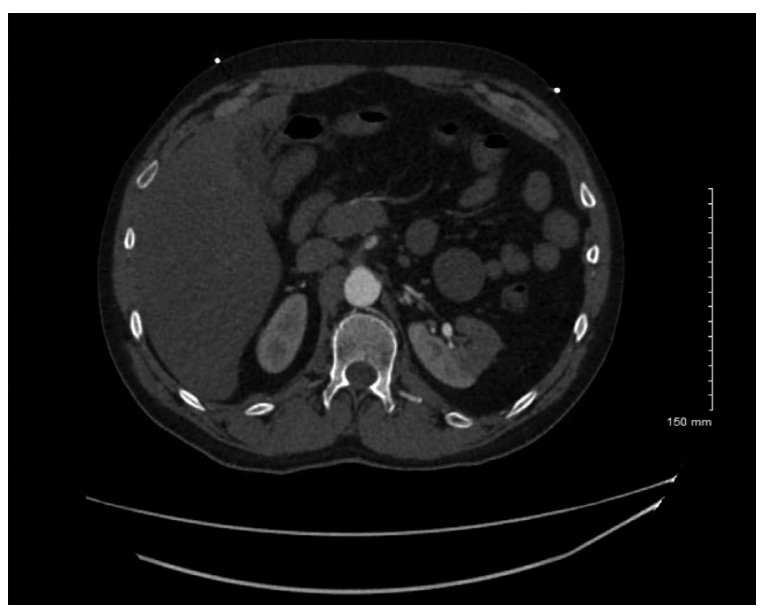

FIGURE 1. Computed tomography scan showing the visceral compromise of the superior mesenteric artery, which resulted in occlusion of the vessel.

perfusion of the visceral vessels and the remaining thoracoabdominal aorta (Video 1).

Postprocedurally, aggressive anti-impulse therapy continued. Postoperative echocardiography showed no pericardial effusion, and computed tomography confirmed successful revascularization of the celiac, superior mesenteric, and renal arteries; despite diffuse bowel-wall thickening, no pneumatosis or portal venous gas was detected. Aggressive fluid resuscitation normalized the lactic acidosis within 48 hours.

On postoperative day 6 , the patient underwent definitive proximal aortic repair. Operative management included axillary artery cannulation, moderate hypothermia $\left(24^{\circ} \mathrm{C}\right)$, and bilateral antegrade cerebral perfusion. The aortic root was replaced with a composite mechanical graft, the coronary arteries were directly reattached (modified Bentall), and the ascending aorta and hemiarch were replaced. Because right ventricular dysfunction was detected during weaning from cardiopulmonary bypass, a saphenous bypass

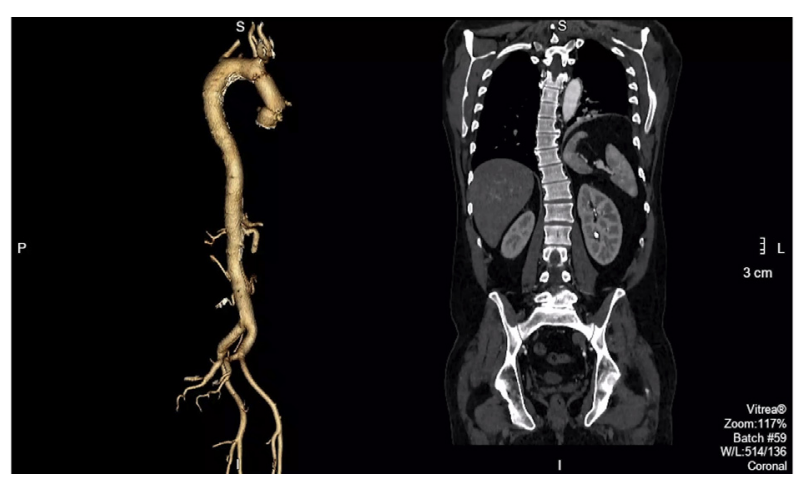

VIDEO 1. Use of the Zenith Dissection Endovascular System to treat visceral malperfusion in a patient with acute type I aortic dissection. Video available at: https://www.jtcvs.org/article/S2666-2507(20)30335-7/fulltext. graft to the right coronary artery was completed on the assumption that the right coronary ostium was compromised.

Intraoperatively, the patient developed profound coagulopathy requiring massive transfusion, which led to hypoxemic respiratory failure necessitating bifemoral venovenous extracorporeal membrane oxygenation. On postoperative day 3 , the patient had normal biventricular function and was weaned from extracorporeal membrane oxygenation. His serum creatinine level had normalized to $0.69 \mathrm{mg} / \mathrm{dL}$ without postoperative dialysis. The patient was discharged home on day 30 without adverse sequelae. Data regarding the case were collected by the surgical staff, and informed consent was obtained.

\section{DISCUSSION}

The PETTICOAT technique was introduced by Nienaber and colleagues ${ }^{2} 14$ years ago to treat complex acute type B aortic dissection. In 2018, the US Food and Drug Administration approved the Zenith Dissection Endovascular System for this use. The system comprises a proximal stentgraft and a distal bare-metal stent.

Open repair of acute type I aortic dissection concomitant with proximal stent-grafting and distal bare-metal stenting by the PETTICOAT technique has been previously described. ${ }^{3}$ A 2-stage strategy has been also mentioned in isolated reports. ${ }^{4,5}$ The Michigan aortic group, working with an interventional radiology team, pioneered upfront fenestration and stenting in one of the largest series yet reported of patients with acute AAD and visceral malperfusion. ${ }^{6,7}$

What makes our case unique is the upfront use of the Zenith Dissection Endovascular System to resolve the visceral malperfusion instead of using fenestration between the true and false lumens, stenting the visceral arteries, or both. Whether this approach led to better future aortic remodeling than fenestration would have is unknown. Definitive upfront repair could have been an option if the patient's presentation had been different and his lactate level were not too high. Another important teaching point is that the relatively quick proximal aortic repair-performed 6 days after thoracic endovascular aortic repair, when the patient's lactic acid level had normalized and his metabolic acidosis had been corrected - prevents aortic rupture due to dissection.

To our knowledge, the use of the Zenith Dissection Endovascular System as a first-line approach in a patient with malperfusion due to acute AAD has not been reported before. We conclude that this approach can be life-saving for such patients.

We appreciate the editorial support of Stephen N. Palmer, PhD, ELS, of the Texas Heart Institute's Section of Scientific Publications. 


\section{References}

1. Di Eusanio M, Trimarchi S, Patel HJ, Hutchison S, Suzuki T, Peterson MD, et al. Clinical presentation, management, and short-term outcome of patients with type A acute dissection complicated by mesenteric malperfusion: observations from the International Registry of Acute Aortic Dissection. J Thorac Cardiovasc Surg. 2013;145:385-90.e1.

2. Nienaber CA, Kische S, Zeller T, Rehders TC, Schneider H, Lorenzen B, et al. Provisional extension to induce complete attachment after stent-graft placement in type B aortic dissection: the PETTICOAT concept. J Endovasc Ther. 2006;13: 738-46.

3. Hsu HL, Chen YY, Huang CY, Huang JH, Chen JS. The Provisional Extension To Induce Complete Attachment (PETTICOAT) technique to promote distal aortic remodelling in repair of acute DeBakey type I aortic dissection: preliminary results. Eur J Cardiothorac Surg. 2016;50:146-52.

4. Firstenberg MS, Sai-Sudhakar CB, Sirak JH, Crestanello JA, Sun B. Intestina ischemia complicating ascending aortic dissection: first things first. Ann Thorac Surg. 2007;84:e8-9.

5. Parsa CJ, McCann RL, Hughes GC. A novel approach to the treatment of distal malperfusion secondary to ascending aortic dissection. J Card Surg. 2010;25: 220-2.

6. Yang B, Norton EL, Rosati CM, Wu X, Kim KM, Khaja MS, et al. Managing patients with acute type $\mathrm{A}$ aortic dissection and mesenteric malperfusion syndrome: a 20-year experience. J Thorac Cardiovasc Surg. 2019;158: 675-87.e4.

7. Yang B, Rosati CM, Norton EL, Kim KM, Khaja MS, Dasika N, et al. Endovascular fenestration/stenting first followed by delayed open aortic repair for acute type A aortic dissection with malperfusion syndrome. Circulation. 2018;138: 2091-103. 